\title{
V ЮБИЛЕЙНЫЙ НАУЧНО-ПРАКТИЧЕСКИЙ СЕМИНАР С МЕЖДУНАРОДНЫМ УЧАСТИЕМ «ОБУЧЕНИЕ ПЕРЕВОДЧЕСКОМУ МАСТЕРСТВУ»
}

\author{
Б. Н. Гайдин \\ (Московский гуманитарный университет)
}

\begin{abstract}
Аннотация: В статье делается обзор работы $V$ Международного научно-практического семинара с международным участием «Обучение переводческому мастерству», который проходил 27-30 мая 2015 г. в Пловдивском университете им. П. Хилендарского (Болгария). В работе семинара приняли участие сотрудники Московского гуманитарного университета.

Ключевые слова: обзор, семинар, переводческое мастерство.

\section{TH RESEARCH SEMINAR AND WORKSHOP WITH INTERNATIONAL PARTICIPATION “TEACHING TRANSLATION PROFICIENCY”}

\author{
B. N. Gaydin \\ (Moscow University for the Humanities)
}

\begin{abstract}
The article presents a summary of the 5th research seminar and workshop on translation proficiency which was held on May 27-30 at Paisii Hilendarski University of Plovdiv, Bulgaria. The list of speakers at the seminar included faculty members of Moscow University for the Humanities
\end{abstract}

Keywords: overview, seminar, translation proficiency.

С 27 по 30 мая 2015 г. в Пловдивском университете им. Паисия Хилендарского (г. Пловдив, Болгария) состоялся V Юбилейный научно-практический семинар с международным участием «Обучение переводческому мастерству», организованный Центром русского языка и культуры Пловдивского университета при содействии кафедры русской филологии Пловдивского университета и при финансовой поддержке фонда «Русский мир».

Семинар проводится вот уже пятый год подряд, в 2014 г. он обрел международный статус. В 2015 г. наряду с болгарскими студентами из Со- 
фийского, Великотырновоского, Шуменского, Варненского свободного и Пловдивского университетов, а также из Академии музыкального, танцевального и изобразительного искусств в нем приняли участие студенты из университетов Белграда, Будапешта, Кракова и Карса (Сербия, Венгрия, Польша и Турция).

В работе форума приняли участие 63 студента-русиста болгарских и иностранных университетов, которые в течение трех дней прошли обучение переводческому мастерству под методическим руководством трех российских специалистов и трех болгарских университетских преподавателей.

Выступившие на открытии семинара ректор Пловдивского университета, профессор, доктор Запрян Козлуджов, представитель посольства РФ в Республике Болгария Роберт Робертович Шестаков и главный эксперт МОН РБ доктор Стоянка Почеканска обозначили как остроту проблемы перевода, так и важность и своевременность инициативы Пловдивского русского центра, поддержанной Фондом «Русский мир» и реализованной при содействии кафедры русской филологии Пловдивского университета.

Программа семинара включала три лекции, три мастер-класса российских специалистов и три практикума перевода текстов разных жанров и профессиональных областей (язык художественной прозы, язык делового общения и язык туристического сервиса), а также два круглых стола, на которых обсуждались феномен языковой игры, языковая личность в переводе, практика болгарских издательств в переводе современной русской литературы.

Участники семинара познакомились с уникальным разносторонним опытом российских и болгарских специалистов и сошлись во мнении, что перевод - это творческая деятельность, искусство, в целях обучения которому необходимо продолжить работу по повышению квалификации русистов и поддержать систему регулярного обмена опытом посредством организации тематических семинаров, мастер-классов, круглых столов и рабочих встреч.

Обращение к языковой личности в процессе перевода стало новым элементом, обогатившим программу форума в этом году.После просмотра интереснейших презентаций домашних заданий, посвященных лингвистическому комментарию языковой игры, в первый день работы семинара студенты всех команд с восторгом прослушали удивительные лекции и мастер-классы русского писателя, лауреата Премии Правительства Российской Федерации в области культуры, лауреата Бунинской премии 2011 года Бориса Тимофеевича Евсеева, доктора философии (PhD), кандидата филологических наук, директора Центра теории и истории культуры Института фундаментальных и прикладных исследований Московского гуманитарного университета, ученого секретаря Шекспировской комис- 
сии РАН Николая Владимировича Захарова и известного поэта, главного редактора журнала «Юность» Валерия Фёдоровича Дударева, активно общались с лекторами и между собой, задавали вопросы и получали ответы на них, наслаждались профессиональным и дружеским общением.

В итоге была подчеркнута востребованность и полезность проведения такого рода форумов для студентов - будущих переводчиков, выбравших своим профессиональным языком русский.

Высоко оценивая инновационный дух этого молодежного форума для поддержки и популяризации русского языка и русской культуры, участники высказали особую благодарность фонду «Русский мир» и исполнителям проекта за проявленную заботу о молодых русистах на пороге их профессиональной реализации.

После получения сертификатов и заполнения анкеты участники семинара выразили свою признательность организаторам за профессионализм и дружескую атмосферу общения и высказали пожелания о ежегодном проведении семинара.

Было высказано мнение, что для развития семинара и повышения эффективности данного формата необходимо расширять географию и профессиональный профиль его участников, обогащать тематику занятий и увеличить продолжительность мероприятия с трех до пяти дней.

Гайдин Борис Николаевич - кандидат философских наук, заместитель директора Центра теории и истории культуры Института фундаментальных и прикладных исследований Московского гуманитарного университета. Адрес: 111395, Россия, г. Москва, ул. Юности, д. 5, корп. 6. Тел.: +7 (499) 374-59-30. Эл. адрес: barbarious@mail.ru

Gaydin Boris Nikolaevich, Candidate of Philosophy, Deputy Director, Center for the Theory and History of Culture, Institute for Fundamental and Applied Studies, Moscow. Postal address: Bldg.6, 5 Yunosti St., 111395 Moscow, Russia. Tel.+7 (499) 374-59-30.Email: barbarious@mail.ru 